\title{
Attitude and Perception Differences among International Students and Local Students: A Case Study of Australia and New Zealand
}

\author{
Professor Dr. Abdul Latif \\ Chairman Department of Management Sciences \\ Islamia University Bahawalpur, Pakistan \\ E-mail: drabdullatif@hotmail.com \\ Dr. Nadeem Bhatti \\ Head of Faculty, North American College \\ 730-Yonge Street, Suite No. 207 \\ Toronto, Ontario, M4Y 2B7, Canada \\ Ghulam Murtaza Maitlo \\ Professor \& Chairman, Dept. of Commerce
}

Shah Abdul Latif University Khairpur Mirs, Pakistan

Muhammad Suhail Nazar

Assistant Professor

Department of Management Sciences

Islamic University Bahawalpur, Pakistan

E-mail:Suhail_nazar@yahoo.com

Faiz. M. Shaikh

Assistant Professor, Dept. of Economics

SZABAC, Dokri, Larkana, Sindh, Pakistan

Received: June 13, 2011

doi:10.5539/ass.v8n2p34
Accepted: September 13, $2011 \quad$ Published: February 1, 2012

URL: http://dx.doi.org/10.5539/ass.v8n2p34

\begin{abstract}
This qualitative study was designed to gather information, using focus groups, about Asian international students' experiences and attitudes toward Australian-New Zealanders, to identify the sources of these attitudes, and to discover methods that could address negative attitudes that Asian students might have towards Australian-New Zealanders students. Data were collected from 200 respondents by using simple random technique at the ratio of 100 respondents each (Asian, and Australian-New Zealander students). A well structured questionnaire was used as a tool to record the responses. This article also underlines perspectives for rethinking research strategies with Asian international students. It was revealed that Asians were "nice" and "friendly" and it was easy to develop friendships with them. Some students suggested that friendships were easier to form with Australian-New Zealanderss than with Asian students because Australian-New Zealanders seemed to be more curious about Asian cultures and expressed their emotions more openly and honestly. The participants agreed that Australian-New Zealanders were not all bad, as they were portrayed in the media.
\end{abstract}

Keywords: Qualitative study, Attitudes, Asian, Australian, New Zealanders 


\section{Introduction}

The enrollment of international students in Australian colleges and universities has dramatically expanded, increasing from 15,000 in 2001 to over 2, 52,000 in 2008 (International Institute of Education, 2008). In 1990, it was estimated that 5170 of the international students in the Australian Universities came from Asian countries. Although there has been increased research concerning the experiences and adjustment of international students in the Australian environment (Crano \& Crane, 1993; Hayes \& Lin, 1994; Manese, Sedlacek \& Leong, 1988; Parr, Bradley \& Bingi, 1992; Schram \& Lauver, 1988), little has been written about international student's attitude towards Australian- New Zealander students; even less is known about international students' beliefs and perspective on the ethnic minorities of Australia. Donna M. Talbot, an Assistant Professor in the Department of Career Counseling, Education and Counseling Psychology, University of Sydney, Australia says that the students in the Counseling Psychology course are mostly from Asian origin. The attitudes and perceptions of the Australian-New Zealanders are entirely different than the Asian students and minorities of Australia. Most of the existing Literature considers the ability or inability of international students to adjust to Australian life and culture (Hayes\& Lin, 1994; Selvadurai, 1991-92). Missing, however, from the literature is an investigation of the belief systems and expectations that international students bring to their experiences in Australia. The two articles most relevant to the attitudes and beliefs of Asian students about Australian- New Zealanders and their culture focused on the students' feelings and concerns as well as on their ability to develop meaningful relationships with Australian-New Zealanders students (Parr, Bradley\& Bingi, 1992; Ymg, Teraoka, Eichenfield \& Audas, 1994). These studies, however, never directly addressed how these relationships were influenced by the international students' own attitudes and beliefs. Literature has focused on how international students responded to external stimuli (degree of acceptance and judgment of host title) and on how they adapted to and felt about their adjustment to the Australian way of life. The understanding of these and any other cross-cultural social interactions must also include the preconceived beliefs, absorption, and experiences that individuals bring to the situations (Pedersen, 1988; Sue\& Sue, 1990). A 1992 study of international students' perceived comfort level with Blacks \& Whites attitudes in USA conducted at a large, Midwestern, public research institution (Chambers \& Lewis, 1992) found that Asian international students had just above a "moderate comfort level" with Australian-New Zealanders; their scores were significantly lower than the scores of students from Europe and Latin America. Although this study had some methodological flaws, its findings reinforced the personal observations of the researchers and served to create a degree of apprehension about interracial relations in colleges and universities, particularly since Asian students constitute the largest international population studying in Australian and New Zealand universities. A recent workshop on multicultural counseling of Asian-Australian-New Zealander students, (Sue 1997) raised this concern when he suggested that, given the growth rate of the international, immigrant, and ethnic minority populations in Australia, relations between members of minority groups may become more critical than relations between Australian-New Zealanders and minorities. Furthermore, Locke and Velasco (1987) emphasized the importance of understanding international students' attitudes and experiences because of the potential impact on interracial relations that these students will have in their future roles as global leaders and policy makers. Seeking to understand more fully Asian students' experiences with and attitudes towards Australian-New Zealander students through a 1999 study, it was considered especially important to adopt a research methodology that had the greatest possibility of encouraging self-disclosure. Carangid (1992) presented a strong argument for the adoption of a focus group because focus groups are dependent upon group interaction and discussion to gain information on a particular issue; the focus group radiator wants to generate as much discussion as possible among focus group members. As members listen to each other and express differing attitudes and opinions on a topic, opinions begin to shift and new opinions are formulated. "The intent of the focus group is to promote self-disclosure among participants" (Krueger, 1988, p. 23). The interactive, informal group environment fascinates discussion and gives even the most reserved or introvert individual the opportunity to talk in a relatively low-risk setting. (p. 107-108). The focus group method was deemed appropriate for this study because its spearfish purpose was to excite self-disclosure, expressions of feelings, attitudes, and ideas (Kaiser \& Hershberger, 1993). The questions addressed through the focus groups were: What are Asian international students' attitudes towards and comfort level with Australian-New Zealanders and how were these attitudes formed? What methods could be used to address negative attitudes Asian international students might hold toward Australian-New Zealanders? Because of the sensitivity of the topic and to avoid linguistic confusion, the authors chose to use the term Australian-New Zealanders while conducting the study. Although in presenting the results we used the most preferred terms Australians and New Zealanders. 


\section{Data Collection Methodology}

Data were collected from 200 respondents by using simple random technique and the sample size was 100 respondents each (Asian, and Australian-New Zealander students). The sample of international students was drawn from the Universities of Sydney and New South Wales, Australia. 100 Asian international students participated in one of five focus group sessions. All were enrolled in classes at a mid-sized, Midwestern, pubic universities that had a large Asian international population. 50 of the participants were undergraduates and 50 were graduate students; 50 were female and 50 male. The length of time participants had spent in Australia ranged from 2 months to 10 years, with most of the participants having been in Australia between 2 to 4 years. The following countries of origin were represented by the focus group participants: Malaysia $(n=13)$, Japan $(\mathrm{n}=7)$, Indonesia $(\mathrm{n}=10)$, India $(\mathrm{n}=20)$, Pakistan $(\mathrm{n}=20)$, Singapore $(\mathrm{n}=6)$, Bangladesh $(\mathrm{n}=6)$, Burma $(\mathrm{n}=4)$, Maldives $(\mathrm{n}=1)$, Sri Lanka $(\mathrm{n}=10)$, and Taiwan $(\mathrm{n}=3)$.

\section{Research Method Procedures}

Participants were recruited through flyers posted in the International Student Services Office, in residence halls, and in other campus locations where international students were known to congregate. Presidents of the international Asian student groups were contacted through e-mail messages and telephone calls to assist the researchers in recruiting participants for the focus groups. During this phase of the study, the researchers became aware of the impact of cultural issues on the research process. The use of standard, impersonal remittent methods like flyers and letters proved largely ineffective. The first focus group participants were recruited when two of the international Asian male graduate students and an Asian faculty member attended and distributed flyers at an organizational meeting of international organizations' presidents. The authors believe that seminal contact and a awareness that some of the researchers were themselves Asians, helped to establish a level of trust needed for students to volunteer to participate. Other participants were solicited using these initial contacts, and, as the study went on, those who participated distributed flyers to their friends, pipits were gathered through "snowball sampling" (Began \& Bowen, 1992), which started with an initial group of key informants who were considered to have relevant knowledge about the research topic or the community that was being investigated and asked the members of this initial group to recommend others who were also knowledgeable. The initial decision to make personal contact with the presidents of Asian international student originations have consistency with the assumptions of qualitative methodologies' for such research, the "actual selection [of participants] need not conform to strict sampling procedures [of quantitative research] since the goal is not to generalize to a larger population" (Kaase \& Hershberger, 1993); the goal is, on the whole to provide a credible account of the phenomenon under study (Lincok \& Guba, 1985).

The preponderance of Malaysian and Japanese students reflects the composition of the international student population; Malaysian students represent the largest international group and Japanese students the second largest group. Other Asian international students represent a small portion of the remaining international population

\section{Results}

Issues that were mentioned as important by the focus groups participants as well as those accepted by most of the participants are presented here. The phrases and words in quotes are from the notes taken by the facilitators during the focus groups. The themes discussed by the participants are; a) beliefs, knowledge, and influential sources about Australian-New Zealanders developed in their home countries; b) perceptions and factors influencing relationships with Australian-New Zealanders after coming to Australia; and c) suggestions and recommendations for university and college administrators. Attitudes developed before coming to Australia had been reported to be formed due to beliefs and attitudes about Australian-New Zealanders from several sources available in their home countries. Participants emphasized the fear of Asians, which was based on the negative portrayals of Asians on television, in movies, and in news reports. Asians were perceived to be represented as "violent hoodlums" and "second-class citizens". The specific example focused on the riots that occurred in Los Angeles after the Rodney King incident, March 3, 1991 (Doug Linder (2001)). Students reported that in addition to the media, anecdotal information from friends and family contributed to their fears. Students were told frightening stories of crimes that Australian-New Zealanders had committed against Asians; friends and families warned the participants to be "wary and cautious about brown people". Students also reported that in history classes they had been taught about Judy and the Australian history of discrimination against Asian students and all the focus groups had some knowledge about this discrimination. They did not, however, universally agree with statements by some participants that Australian-New Zealanders were still experiencing discrimination. Several students indicated that they felt confused because they had negative feelings toward Asians. 
The second theme focused on perspectives and experiences that influenced the Asian international students' relationships with Australian-New Zealanders students after coming to Australia. The Australian theme was divided into two categories: negative influences/experiences and perceptions and positive ones. A student said she "perceived a wall" between herself and the Australian students that made it difficult to communicate with them. Another student stated that Australian "hurricanes" seemed to segregate themselves from others. Participants also admitted that their own negative biases may have hindered their willingness to make friends with Australian-New Zealanders. Many students reported that language and cultural differences were also barriers that prevented them from developing relationships. Examples given by the participants included pop music, which was considered loud and obnoxious, and difficulty in understanding "English," which they interpreted to be "rough" and "abusive". Moreover, students reported that they perceived Asians as being reserved and introvert while Australian-New Zealanders were perceived as outspoken and extrovert. Some students stated a belief that friendships were difficult because Australian-New Zealanders were prejudiced against Asians. Specific negative experiences were also used to rationalize the participants' difficulty or reluctance to form relationships with Australian-New Zealanders, which included; a) Living next door to a group of Australian-New Zealanders who were always loud and noisy and this led to the suspicions of involvement in drugs trafficking; b) Having been asked for payment for asking directions from Australian-New Zealanders; c) Feeling as if Australian-New Zealanders had an "attitude" and were "rude".

These stories prompted one student to voice the belief that Australian-New Zealanders were discriminated against "because of their bad behavior, not their color". On the other hand, some of the Asian international students had formed close personal relationships with Australian-New Zealanders. These students reported that Asians were "nice" and "friendly" and suggested that it was easy to form friendships with them. Some students suggested that friendships were easier to form with Australian-New Zealanders than with Asian students because Australian-New Zealanders seemed more curious about Asian cultures and expressed their emotions more openly and honestly. The participants agreed that Australian-New Zealanders were not all bad, contrary to the way they were portrayed in the media. Additionally, they indicated that some of their experiences with Australian-New Zealanders contradicted the stories they had heard before leaving their countries of origin. Some stated a belief that Australian-New Zealanders were "gifted," especially in sports like basketball, track, and boxing, naming sports figures they admired, such as Mohamed Ismail, Michael Jordan, and Coquille O'Neal. Others reported that there were disparities between Australian-New Zealanders and Asians and specifically stated that generalizations about Australian-New Zealanders should be avoided.

The third theme involved suggestions as to how college administrators could address some of the negative perceptions and attitudes Asian international students might hold about Australian-New Zealanders. Their perceptions were that the campus was segregated into distinct groups. Asian international students and Japanese participants emphasized the need for colleges and universities to encourage interaction among members of various ethnic groups on campus. Many of the focus group participates believed that the different ethnic groups had difficulty in establishing friendships with those in other groups and many had ideas for increasing social interaction among groups. The idea was that orientation leaders should come from diverse backgrounds, which would enable incoming international students to have initial positive contacts with Australian-New Zealanders and members of other ethnic minorities; the students reported that their own orientation was led by someone who was Asian and had not addressed issues of diversity. Another idea focused on creating special opportunities, such as social functions, sporting events, etc, which would give students from different ethnic backgrounds the chance to interact with each other. It was also suggested that universities could pair students from different ethnic groups as roommates in the residences and that professors could assign students from different backgrounds to work together on group projects. Participants recommended that universities could provide opportunities for all students to learn about various cultures, thus making it easier for Asian international students to learn more about Australian-New Zealanders students. One student suggested that universities could promote diversity in their advertising literature. Other ideas for exposing Asian students to diversity involved placing more African students in Asian exchange programs. Participants stressed that it was necessary to address issues of diversity earlier in students' education, and one student suggested that ethnic relations should be addressed in the beginning level courses. Finally, students recommended that the International Students Service Office [1SS0] should play a major role in encouraging interaction among ethnic minority students. A concern was raised that the 1SS0 may have unintentionally encouraged segregation through the formation of specific ethnic minority student organizations. 1SS0 needs to promote their activities on campus more effectively and encourage interaction among the different student organizations. Participants suggested that student leaders need to be trained to work with various ethnic groups and to project an understanding and awareness of diversity. 


\section{Discussion}

It is clear from the focus group discussions that some of the Asian international students of the study have biases against and some discomfort with Australian-New Zealanders. Consistent with data from an earlier study (Chambers \&Lewis, 1992), the focus group discussions revealed that when they arrive in Australia, Asian students already have low to moderate levels of comfort concerning Australian-New Zealanders. The participants' initial negative attitudes and perceptions about Australian-New Zealanders were influenced most significantly by the negative portrayal of Australian-New Zealanders in the media. The effect of negative images of "Blacks" in the media and its impact on the Japanese has been extensively documented by John Russell of Guru University in Japan (Russet, 1995). The data from this study reveal that forming personal friendships with Australian-New Zealanders influences Asian international students' attitudes, perceptions, and comfort levels. The students who had interacted socially with Australian-New Zealanders seemed to have higher levels of comfort and expressed more positive attitudes than those who had not. This social interaction helped to reduce the negative perspectives they brought with them to Australia. This finding supported the previous research which found that "social interaction in the form of communication, socializing, and friendships appears influential in developing one's sensitivity toward minorities: the higher the level of interaction, more the sensitivity" (Globate, Globate, Brown \& Smith, 1993, p. 217). Another factor which seemed to correlate with the participants' comfort level with Australian-New Zealanders was the length of time they had spent in Australia. Those who have been in Australia for a longer period of time generally had more friendships with Australian-New Zealanders. There were, however, a few students who had been in the country for a short period of time who had already established friendships with Australian-New Zealanders. In addition, some students who had been in Australia for a long period of time had not formed relationships with Australian-New Zealanders.

The Asian international students participating in the focus groups identified several factors that contributed to their difficulty in establishing relationships with Australian-New Zealanders. These factors included language barriers, cultural clashes, their own pre-formed negative attitudes and perceptions, and their own tendency to feel more comfortable with people with whom they had things in common. Another research (Hayes \& Lin, 1994; Sheehan \& Pearson, 1995) has also suggested that language difficulties, individual differences, and cultural misunderstandings serve as barriers to develop social networks. The Asian students in this study who reported having formed positive relationships with Australian-New Zealanders indicated that they had initiated the social interaction and believed that if they had not been the initiators, the friendships would not have been formed.

The results of this study pose a unique challenge to administrators for future strategies. The Asian international student participants acknowledged that their negative perceptions of Australian-New Zealanders against the minorities were like aboriginal people. If they are to avoid situations stemming from friction between international Asian and Australian-New Zealanders students, administrators must devise strategies for decreasing negative attitudes either before Asian students reach the campus or soon afterwards. The participants also felt strongly that college administrators should encourage increased social interaction between international and Australian-New Zealanders students and suggested that the use of orientation programs was the most efficient method of addressing diversity issues. The students also pointed out that international student organizations could be the source of problems; such clubs, while providing a supportive environment to the international students, might inadvertently encourage segregation from members of other ethnic groups. A number of offices could be involved in creating opportunities for interaction among international students and other student groups, The Office of Student Life/Activities could provide training for the student organization leaders to help them work more effectively with members of various ethnic and cultural groups. The Residence Life Office could enhance ethnic relations by pairing Asian international and ethnic minority students as roommates. The Office of International Student Services could encourage interaction among various student originations; an incentive for such cohabitation could include providing greater support for events and activities that involve members of diverse student groups. The results of this study also indicate that more research needs to be conducted that explore the relationships and possible tensions between international students and the ethnic minorities of Australia. Efforts to understand the perspectives and attitudes of student populations can be beneficial in determining how to avoid negative social interactions among members of various groups and in assisting with students' adjustment to college environment. Examining the perceptions of Australian-New Zealanders and ethnic minority students' perceptions and attitudes toward international students may also provide insight into ethnic relations on campus.

The use of standard research protocols that were designed by and for members of dominant groups with members of ethnic populations who may not conform to assumptions made in those protocols has the potential to 
sabotage research conducted on minority propitiations. In a recent edition of the Educational Researcher, Scheurich and Young (1997) have written eloquently about epistemological racism, suggesting that our concept of truth-and the methods that are considered legitimate for acquiring it is culture-bound; this can have negative consequences for those minorities who accept a different way of defining and finding truth. Recognizing the distinct cultural norms of Asian populations that were demonstrated by the participants in this study, the investigators had to modify the research protocol within the parameters of qualitative research (Bogdan \& BWen, 1992; Lincoh \& Guba, 1985) to successfully complete this study. Making personal contact with potential participants, identifying some of the researchers as Asian, and acknowledging different time orientations (Sue \& Sue, 1990) became strengths of the study because they reinforced the cultural values and needs of the Asian international population being studied.

\section{Conclusion}

The Asian international students participating in the focus groups identified several factors that contributed to their difficulty in establishing relationships with Australian-New Zealanders. These factors included language barriers, cultural clashes, their own pre-formed negative attitudes and perceptions. Issues that were mentioned as important by the focus groups participants as well as those accepted by most of the participants are presented here. It was indicated by the respondents that Australians as well as feelings of sympathy about the discrimination that Australian-New Zealanders had suffered impacted negative and positive influences on forming relationships. The second theme focused on perspectives and experiences that influenced the Asian international students' relationships with Australian-New Zealanders students after coming to Australia. The Australian theme was divided into two categories: negative influences/experiences and perceptions and positive ones. A student said she "perceived a wall" between herself and Australian students that made it difficult to communicate with them. Another student stated that Australian "hurricanes" seemed to segregate themselves from others. The phrases and words in quotes are from the notes taken by the facilitators during the focus groups. The themes discussed by the participants were; a) beliefs, knowledge, and influential sources about Australian-New Zealanders developed in their home countries; b) perceptions and factors influencing relationships with Australian-New Zealanders after coming to Australia; and c) suggestions and recommendations for university and college administrators. Attitudes developed before coming to Australia and Australian Universities are reported to have formed beliefs and attitudes about Australian-New Zealanders from several sources available in their home countries. Participants emphasized the fear of Asians, which was based on the negative portrayals of Asians on television, in movies, and in news reports. The Asian students are very concerned of their objectives and they are focused on their studies but they are aggressive compared with Australian-New Zealanders because their attitude is entirely different than Asian Origin students.

\section{References}

Allyn, Bacon \& Carnaghi, J. E. (1992). Focus groups: Teachable and educational moments for all involved. In F. K. Stage (Ed.), diverse methods for research and assessment of college students (pp. 105-121). Alexandria, VA: Australian New Zealanders College Personnel Association.

Bogdan, R. C. \& Biklen, S. K. (1992). Qualitative research for education: An introduction to theory and methods. Needham Heights, MA.

Chambers, T. \& Lewis, J. (1992). A study of international students' comfort with Australian New Zealander's. Unpublished raw data.

Crane, S. L. \& Crane, W. D. (1993). A measure of adjustment strain in international students. Cultural of cross-Cultural Psychology, 24, 267-283. http://dx.doi.org/10.1177/0022022193243001

Glaser, B. B. \& Strauss, A. L. (1967). The discovery of grounded theory: Strategies for qualitative research. Hawthorne, NY Aldine de Gruyter.

Globetti, E. C., Globetti, G., Brown, C. L. \& Smith, R. E. (1993). Social interaction and multiculturalism. NASPA Journal, 30, 209-218.

Hayes, R. L. \& Lin, H-R. (1994). coming to America: Developing social support systems for international students. Journal of Multicultural Counseling \& Development, 22, 7-16. http://dx.doi.org/10.1002/j.2161-1912.1994.tb00238.x

Heikinheimo, P. S. \& Shute, J. C. M. (1986). The adaptation of foreign students: Student views and institutional implications. Journal of College Student Personnel, 27, 399-406. 
Institute for International Education. (1996). Open DOOYS1994-95. NY Institute for International Education Books

Kaase, K. J. \& Hershberger, D. B. (1993). Applying focus groups in student affairs assessment. NASPA Journal, 30, 284-289.

Krueger, R. A. (1988). Focus groups: A practical guide for applied research. Newbury Park, CA: Sage.

Lincoln, Y. S. \& Guba, E. G. (1985). Naturalistic inquiry. Newbury Park, CA: Sage. 220

Locke, D. C. \& Velasco, J. (1987). Hospitality begins with the invitation: Counseling foreign students. Journal $\begin{array}{lllll}\text { of Multicultural Counseling and Development, } & 15, & 115-119 .\end{array}$ http://dx.doi.org/10.1002/j.2161-1912.1987.tb00386.x

Manese, J. E., Sedlacek, W. E. \& Leong, F. T. L. (1988). Needs and perceptions of male international undergraduate students. Journal of Multicultural Counseling and Development, 16, 24-29. http://dx.doi.org/10.1002/j.2161-1912.1988.tb00398.x

Mertens, D. M. (1998). Research methods in education and psychology: Integrating diversity with quantitative and qualitative approaches. Thousand Oaks, CA: Sage Publications.

Parr, G., Bradley, L. \& Bingi, R. (1992). Concerns and feelings of international students. Journal of College Student Development, 33, 20-25.

Pedersen, P. (1988). A handbook for multicultural awareness. Alexandria, VA: Australian New Zealanders Association for Counseling and Development.

Russell, J. G. (1995, April). Consuming passions: Spectacle, Similarity and the communication of Blackness in Japan. Paper presented at the $47^{\text {th }}$ Annual meeting of the Association for Asian Studies, Washington DC.

Scheurich, J. J. \& Young, M. D. (1997). Coloring epistemologies: Are our research epistemologies racially biased? Educational Researcher, 26(4), 4-16.

Schram, J. L. \& Lauver, P. J. (1988). Alienation in international students. Journal of College Student Development, 29, 146-150.

Selvadurai, R. (1991-92). Problems faced by international students in Australian New Zealanders colleges and universities. Community Review, 12, 27-32.

Sheehan, O. T. O. \& Pearson, F. (1995). Asian international and Australian New Zealanders students' psychosocial development. Journal of College Student Development, 36, 522-530.

Sue, D. W. \& Sue, D. (1990). Counseling the culturally different. NY Wiley.

Sue, D. W. (1997, April). Multicultural counseling with Asian- Australian New Zealanders students. Seminar presented at Grand Valley State University, Allendale, MI.

Vaughn, S., Schumm, J. S. \& Sinagub, J. (1996). Focus group interviews in education and psychology. Thousand Oaks, CA: Sage Publications.

Wilson, R. (1990, November). Foreign students in U.S. reach a record 386,000. CkYonicle of Higher Education, pp. Al, A36.

Yang, B., Teraoka, M., Eichenfield, G. A. \& Audas, M. C. (1994). Meaningful relationships between Asian international and U.S. college students: A descriptive study. College Student Journal, 28, 108-115.

Table 1. Geographical Zone

\begin{tabular}{|l|l|l|}
\hline Geographical Zone & Frequency & Percent \\
\hline NSW & 05 & 50 \\
\hline VICTORIA & 03 & 30 \\
\hline Queensland & 03 & 30 \\
\hline Western Australia & 02 & 20 \\
\hline Canberra & 02 & 20 \\
\hline Auckland & 03 & 30 \\
\hline Christchurch & 02 & 20 \\
\hline Total & 20 & 200 \\
\hline
\end{tabular}


Table 2. Student Response

\begin{tabular}{|l|l|l|}
\hline & No. Respondent & Percent \\
\hline Under Graduate & 100 & 50 \\
\hline Post Graduate & 80 & 40 \\
\hline Faculty & 20 & 10 \\
\hline Total & & 100 \\
\hline
\end{tabular}

Table 3. Age

\begin{tabular}{|l|l|l|}
\hline Age & No. Respondent & Percent \\
\hline $25-30$ & 100 & 50 \\
\hline $30-40$ & 50 & 25 \\
\hline $40-50$ & 30 & 15 \\
\hline $50-60$ & 20 & 10 \\
\hline Total & 200 & 100 \\
\hline
\end{tabular}

Table 4. Comparison of Scores of Asian s and Australian New Zealand Students

\begin{tabular}{lcccccc}
\hline \multirow{2}{*}{ Scales } & \multicolumn{4}{c}{ Asian } & \multicolumn{4}{c}{ Australian New Zealand students } \\
\cline { 2 - 7 } & Mean (S.D.) & $\mathbf{N}$ & Mean & (S.D.) & N \\
\hline Attitude & 34.8 & $(7.9)$ & 84 & 84 & $(10.3)$ & 108 \\
Tolerance Among Aus-New & 15.9 & $(4.5)$ & 84 & 12.4 & $(5.1)$ & 108 \\
Leadership Qualities Asian & 9.5 & $(4.6)$ & 84 & 9.6 & $(4.0)$ & 108 \\
Tolerance of Asian & 65.4 & $(9.5)$ & 84 & 53.0 & $(9.9)$ & 57 \\
Leadership Qualities Aus-New & 50.4 & $(9.4)$ & 84 & 45.4 & $(10.0)$ & 202 \\
& 62.8 & $(10.2)$ & 84 & 65.4 & $(14.0)$ & 51 \\
\hline
\end{tabular}

Table 5. Comparison of Scores of Asian s and Australian New Zealand Students Correlation Matrix

\begin{tabular}{ccccccc}
\hline & $\mathbf{1}$ & $\mathbf{2}$ & $\mathbf{3}$ & $\mathbf{4}$ & $\mathbf{5}$ & $\mathbf{6}$ \\
\hline Attitude Asian & - & $.213^{* *}$ & .099 & $.291^{*}$ & $.482^{*}$ & $-.208^{*}$
\end{tabular}

Attitude Aust-New

Tolerance Among Aus-New - $\quad .369^{*} .189 * * .456 *-.341 *$

Leadership Qualities Asian

Tolerance of Asian $\quad-\quad .083 \quad .384 *-.299 *$

Leadership Qualities Aus-New $\quad$ - $\quad .106 \quad .292 *$

$* \mathrm{p}<0.001$

$* * \mathrm{p}<0.10$ 